Loma Linda University

TheScholarsRepository@LLU: Digital Archive of Research, Scholarship \& Creative Works

Loma Linda University Electronic Theses, Dissertations \& Projects

6-2017

\title{
An Examination of the Moderating Effect of Proactive Coping in NICU Nurses
}

Britan M. Moore

Follow this and additional works at: http://scholarsrepository.llu.edu/etd

Part of the Clinical Psychology Commons, $\underline{\text { Critical Care Nursing Commons, and the Maternal, }}$ Child Health and Neonatal Nursing Commons

\section{Recommended Citation}

Moore, Britan M., "An Examination of the Moderating Effect of Proactive Coping in NICU Nurses" (2017). Loma Linda University Electronic Theses, Dissertations \& Projects. 427.

http://scholarsrepository.llu.edu/etd/427

This Thesis is brought to you for free and open access by TheScholarsRepository@LLU: Digital Archive of Research, Scholarship \& Creative Works. It has been accepted for inclusion in Loma Linda University Electronic Theses, Dissertations \& Projects by an authorized administrator of TheScholarsRepository@LLU: Digital Archive of Research, Scholarship \& Creative Works. For more information, please contact scholarsrepository@llu.edu. 


\title{
LOMA LINDA UNIVERSITY
}

School of Behavioral Health

in conjunction with the

Faculty of Graduate Studies

An Examination of the Moderating Effect of Proactive Coping in NICU Nurses

by

Britan M. Moore

\begin{abstract}
A Thesis submitted in partial satisfaction of the requirements for the degree

Doctor of Philosophy in Clinical Psychology
\end{abstract}

June 2017 
(C) 2017

Britan M. Moore All Rights Reserved 
Each person whose signature appears below certifies that this thesis in his/her opinion is adequate, in scope and quality, as a thesis for the degree Doctor of Philosophy.

, Chairperson

Kriston Schellinger, Associate Professor of Psychology

Cameron L. Neece, Associate Professor of Psychology

David A. Vermeersch, Professor of Psychology 


\section{ACKNOWLEDGMENTS}

I would first like to thank my committee chair, Dr. Kriston Schellinger, for your support and guidance throughout this process. Thank you to my committee members, Dr. David Vermeersch and Dr. Cameron Neece for your advice and direction. A special thank you to my family and loved ones for their endless support and words of encouragement. I also want to thank the Loma Linda University School of Behavioral Health for providing financial support for this project through a Seed Grant. Finally, thank you to all of the NICU nurses who took the time out of their busy schedules to participate and make this study possible. 


\section{CONTENT}

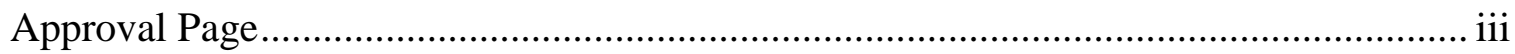

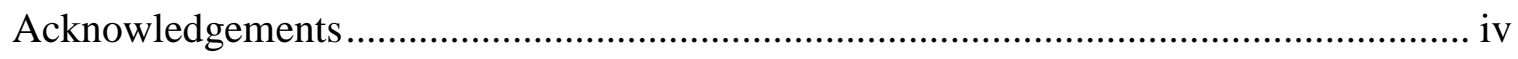

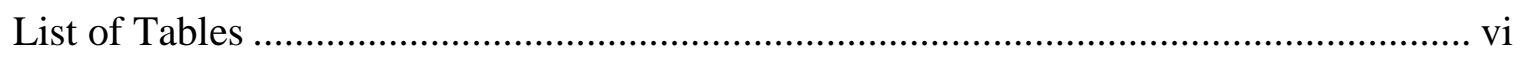

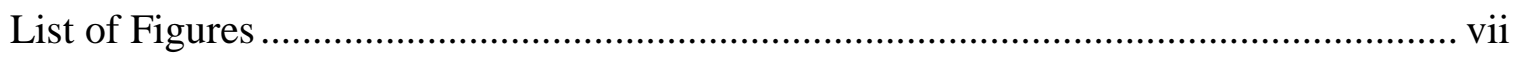

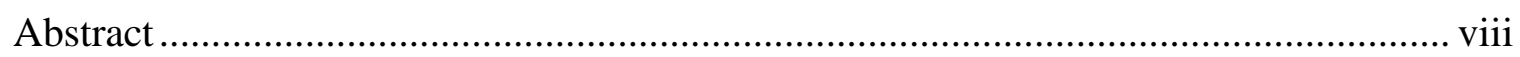

Chapter

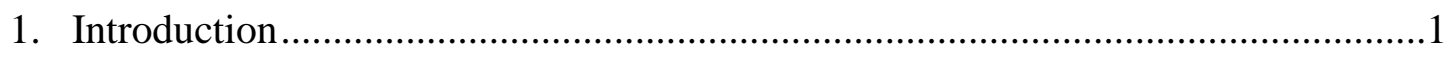

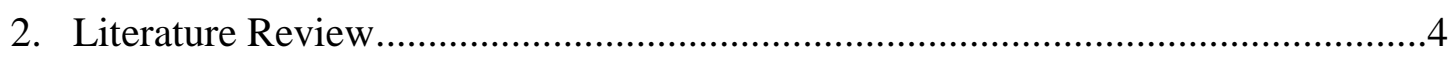

Secondary Traumatic Stress.......................................................................4

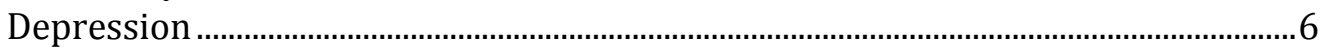

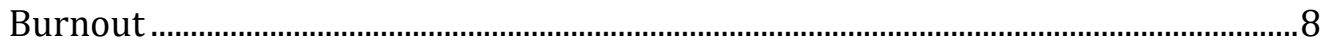

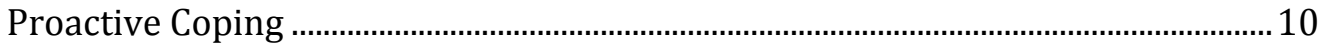

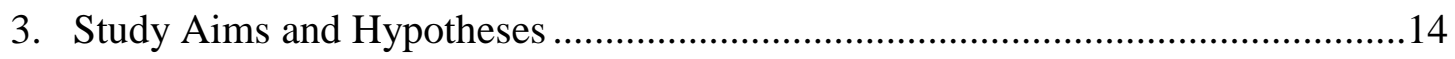

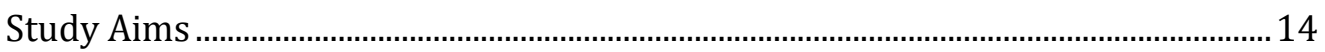

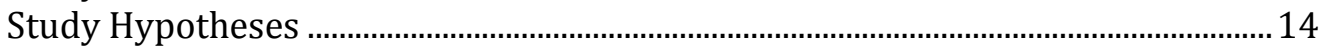

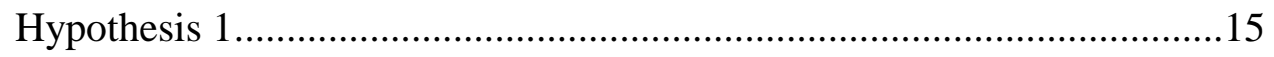

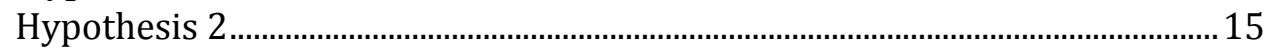

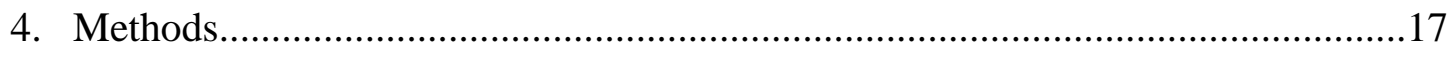

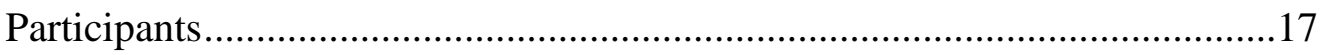

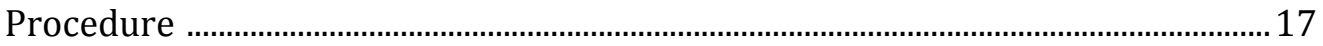

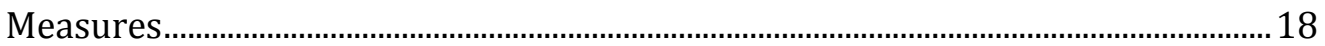

The Professional Quality of Life Scale...................................................................18

The Center for Epidemiological Studies Depression Scale ................................19

The Brief COPE ..........................................................................................................

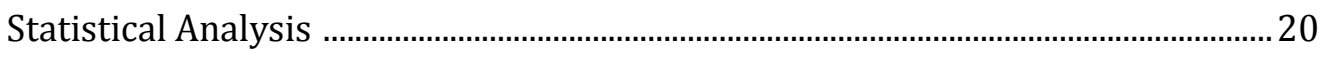

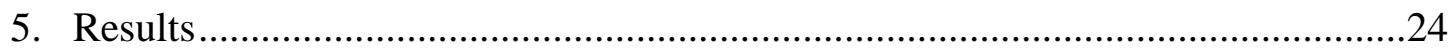

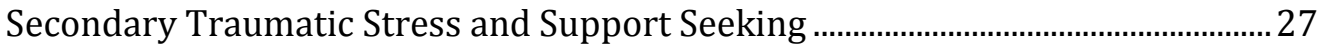

Depression and Problem Solving …………............................................................... 31 


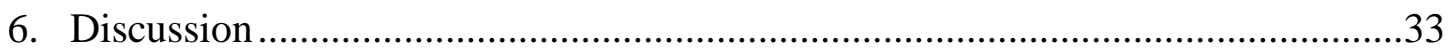

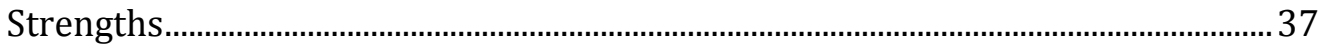

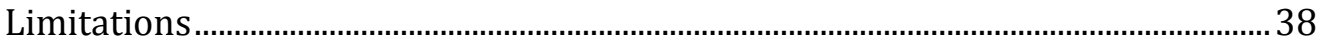

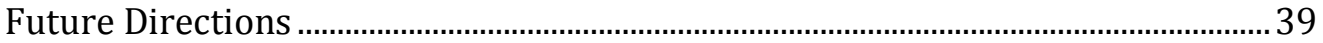

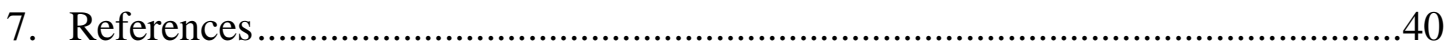

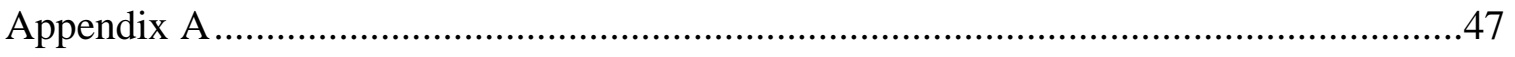

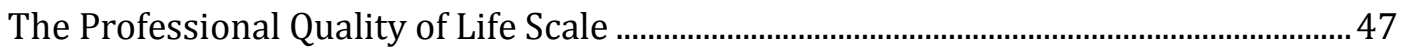

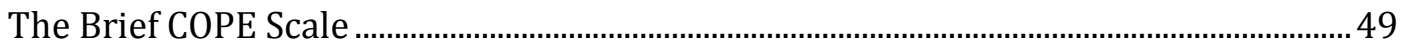

The Center for Epidemiological Studies Depression Scale ................................51 


\section{TABLES}

Table

Page

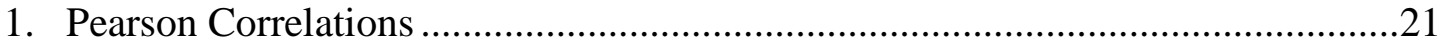

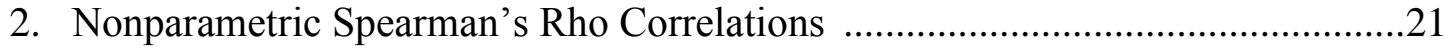

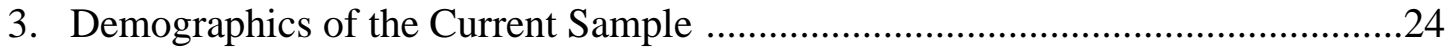

4. Regression and Post-hoc Findings for Secondary Traumatic Stress, Depression, and Traumatic Stress and Support Seeking Interaction ....................30 


\section{FIGURES}

Figure

Page

1. Path diagram for moderation analysis evaluating social support coping strategies as a moderator of the relationship between secondary traumatic stress symptoms and burnout symptoms in NICU nurses

2. Path diagram for moderation analysis evaluating problem solving coping strategies as a moderator of the relationship between depressive symptomology and burnout symptoms levels in NICU nurses. 


\section{ABSTRACT OF THE THESIS}

An Examination of the Moderating Effect of Proactive Coping in NICU Nurses by

\section{Britan M. Moore}

\section{Doctor of Philosophy, Graduate Program in Clinical Psychology Loma Linda University, June 2017 \\ Dr. Kriston Schellinger, Chairperson}

The NICU environment is unique in that the patient population consists of critically ill neonates. Research has revealed that there are increased levels of depression, secondary traumatic stress, and burnout in nurses. Problem solving and support seeking coping strategies have been shown to be associated with lower levels of burnout and increased patient and job satisfaction in general staff nurses. Multiple linear regression and a hierarchical stepwise technique was used to conduct moderator analyses assessing whether the use of problem solving or support seeking strategies moderated the relationship between secondary traumatic stress levels and burnout as well as between depressive symptomology and burnout in NICU nurses. Of the 62 participants, the majority identified as White (64.5\%) and female (98.4\%) with a mean age of 41.65 years $(S D=13.05)$. Support seeking coping skills significantly moderated the relationship between secondary traumatic stress symptoms and burnout symptoms in NICU nurses. Post-hoc analysis indicated that NICU nurses who reported higher levels of secondary traumatic stress symptoms and engaged in higher levels of support seeking coping skills, also reported higher levels of burnout when compared with nurses who reported lower levels of support seeking coping skills. Problem solving coping did not moderate the relationship between depressive symptoms and burnout. These results indicate the need to 
better understand the risk and protective factors related to stress and burnout in NICU nurses. These findings can be used to inform the development of programs that could promote the well-being and coping of nurses experiencing mental health difficulties or burnout and foster a healthy work environment for all NICU nurses so that they can provide the best possible intervention to the vulnerable infants they work with. 


\section{CHAPTER ONE \\ INTRODUCTION}

Nurses frequently experience death and other extreme patient circumstances in the context of their job (Beck, 2011). The fast-paced environment of critical care units is particularly stressful because nurses are exposed to critically ill patients and if a patient dies, nurses are often not provided with an opportunity to address and resolve the losses they experience during their shift due to the other job demands they face (Mallett, Price, Jurs, \& Slenker, 1991). As such, critical care nurses, in particular, report more occupational stress, greater burnout, and more anxiety than other nurses (Mallett et al., 1991). Furthermore, Intensive Care Unit (ICU) nurses commonly report psychological disorders such as Posttraumatic Stress Disorder, anxiety, depression, and burnout syndrome (Mealer et al., 2012). The Neonatal Intensive Care Unit (NICU) is an environment that puts nurses at an increased risk of developing negative psychological effects due to the fact that NICU nurses are constantly faced with the pain and suffering of young infants, a chaotic work pace, and continuous demands from their critically ill infant patients as well as the parents of their patients (Dessy, 2009). Despite these risk factors, there has been a lack of research regarding the mental well-being of nurses working specifically in the NICU.

Critical care nurses are often exposed to the traumatizing incidents of others several times throughout one work shift (Keenan \& Royle, 2007). Constant exposure to trauma can result in the development of Secondary Traumatic Stress Syndrome and has debilitating effects on the mental and physical well-being of nurses (Figley, 1995). NICU nurses are surrounded by frail and vulnerable newborns as well as families traumatized 
by the condition of their newborn (Dessy, 2009). While secondary traumatic stress has been repeatedly studied in Intensive Care Unit (ICU) and emergency room nurses, there is a lack of information regarding how secondary traumatic stress may impact NICU nurses specifically.

In addition to traumatic stress, research has revealed that critical care nurses are also at risk for developing increased levels of anxiety and depression (Harris, 1989; Keenan \& Royle, 2007). For example, Gentry, Foster, and Froehling (1972) found that ICU nurses reported high levels of depression and hostility. Consequently, nurses with increased levels of depression may also exhibit lower levels of job performance (Ohler, Kerr, \& Forbes, 2010) and decreased productivity (Lerner \& Henke, 2008). NICU nurses have been found to report higher levels of depression compared to other nurses (Fujimaru et al., 2012). However, there has been a lack of research investigating depression in nurses in general (Chang, Wang, Li, \& Liu, 2011; Ohler et al., 2010), and research investigating levels of depression specifically in NICU nurses has been almost nonexistent.

Conversely, the prevalence of burnout syndrome has been extensively examined in ICU nurses (Bakker, Le Blanc, \& Schaufeli, 2005; Teixeira, Ribeiro, Fonseca, \& Carvalho, 2014). Burnout syndrome develops as a result of exposure to chronic stress (Awa, Plaumann, \& Walter, 2010; Westermann, Kozak, Harling, \& Nienhaus, 2014). Increased levels of burnout negatively affect the well-being of nurses as well as the quality of the work environment (Austin, Goble, Leier, \& Byrne, 2009). Research has also emphasized that higher levels of depression are correlated with higher levels of burnout and lead to decreased levels of job satisfaction in nurses (Glass, McKnight, \& 
Valdimarsdottir, 1993). Furthermore, the experiences of secondary traumatic stress and burnout often overlap in nurses (Cieslak et al., 2014). The NICU has been described as a “breeding ground" for the development of burnout syndrome (Dessy, 2009). However, while research has examined the impact of these factors on the mental and physical wellbeing of ICU nurses, the relationship between burnout syndrome, depression, and secondary traumatic stress levels in NICU nurses has been mostly unexamined.

Although interventions aimed at addressing levels of burnout in nurses have been largely unsuccessful (Awa et al., 2010; Moody et al., 2013), some research has revealed that nurses who utilize proactive coping strategies report lower levels of burnout (Chang \& Chan, 2015). Furthermore, Zhao and colleagues (2002) found that nurses who did not utilize proactive coping strategies exhibited an increased risk of developing mental health problems. However, to the best of our knowledge, no research has examined the use of proactive coping strategies in NICU nurses. As previously stated, NICU nurses are at an increased risk for developing high levels of depression, secondary traumatic stress, and burnout (Cieslak et al., 2014; Glass et al., 1993; Morrissy et al., 2013). Therefore, it is important to examine the influence of proactive coping styles on levels of secondary traumatic stress, depression, and burnout in NICU nurses in order to promote the physical and mental health of NICU nurses. The current study specifically investigated the influence of support seeking coping strategies on levels of secondary traumatic stress and burnout in NICU nurses, as well the influence of problem solving coping strategies on levels of depression and burnout in NICU nurses. 


\section{CHAPTER TWO}

\section{LITERATURE REVIEW}

The NICU environment is unique in that the patient population consists of critically ill neonates (Beal \& Quinn, 2002). Babies are admitted to the NICU for a variety of reasons including premature birth (e.g., born prior to 36 weeks gestational age) or being born with a medical condition that requires immediate intervention (Stacey, Osborn, \& Salkovskis, 2015). Every year, approximately half a million babies in the United States are admitted to the NICU (Hall, 2016). The highly technical and medically focused NICU is vital in giving babies the best possible chance at life, and a growing body of research has demonstrated that the lives of babies and families are shaped by their experience in the NICU environment (Stacey et al., 2015). However, the NICU can also be a highly overwhelming environment for both parents and health care practitioners (Beal \& Quinn, 2002; White-Traut, 2015). For example, previous research has revealed ways in which time spent in the NICU is uniquely stressful, including the physical environment, the baby's physical appearance or behavior, staff-parent interactions, and alterations in the parental role (Stacey et al., 2015). Nurses are on the front line of providing care and managing the NICU environment and have a unique role in protecting preterm infants to support optimal developmental outcomes (White-Traut, 2015). Therefore, it is important to better understand risk (i.e., traumatic stress, depressive symptoms) and protective (i.e., proactive coping) factors experienced by NICU nurses in the context of their job working with critically ill infants and their families. 


\section{Secondary Traumatic Stress and Vicarious Trauma}

Nurses are at risk for experiencing vicarious trauma or secondary traumatic stress as a result of constantly being exposed to the traumatic experiences of others in their daily lives (Keenan \& Royle, 2007). In the medical field, secondary traumatic stress is described as feelings of intrusion, avoidance, and arousal that can develop when an individual is affected by the traumatic experience of their patient (Devilly, Wright, \& Varker, 2009). Similarly, vicarious trauma is defined as the cumulative effect of working with survivors of traumatic events (Devilly et al., 2009). Pearlman and Saakvitne (1995) assert that vicarious trauma is an occupational hazard for nurses and other health professionals who care for and support trauma survivors. Nurses are particularly prone to the experience of secondary traumatic stress because of exposure to their patient's accounts of traumatic events and the experience of reliving terror, grief, and yearning through their empathic engagement with their patients (Keenan \& Royle, 2007).

Vicarious trauma develops over time and can have many debilitating effects on nurses, both physically and mentally (Dane \& Chachkes, 2001; Mealer et al., 2009). For example, individuals who experience vicarious trauma report higher levels of anxiety, depression, somatic complaints, and fatigue in addition to post-traumatic stress reactions (Adriaenssens, de Gucht, \& Maes, 2012). Nurses have also reported emotional numbing, nightmares, headaches, irritability, distancing, and spiritual and moral suffering as a result of trauma faced at work (Clark \& Gioro, 1998; Mealer et al., 2009). Vicarious trauma has also been linked to the development of symptoms of Posttraumatic Stress Disorder (PTSD) in nurses confronted with severe injuries, death, suicide, suffering, and verbal or physical aggression perpetrated by patients or their families (Adriaenssens et 
al., 2012; Crabbe, Bowley, Boffard, Alexander, \& Klein, 2004). For example, nurses working in ICUs report nightmares as a result of experiencing end of life issues more frequently than nurses working in other settings (Mealer et al., 2009). In addition to physical and mental health concerns, vicarious trauma and secondary traumatic stress is associated with the development of a negative work outlook and decreased levels patient care (Mealer et al., 2009). Thus, secondary traumatic stress may exert negative effects on both nurses and their patients.

Although all nurses are at risk for experiencing secondary traumatic stress, nurses working in the NICU are at an increased risk due to the moral distress associated with working with vulnerable infants and their families (Kain, 2007; Klein, 2009).

Furthermore, the constant exposure to loss and death constitutes an enormous burden for nurses (Mallett et al., 1991). Death is an even more traumatic event for nurses who work in the NICU taking on the primary care of newborns (Polat et al., 2013). Unfortunately, despite being recognized as an environment high in moral distress and exposure to end of life events, little to no research has investigated the levels of secondary traumatic stress experienced by nurses working in the NICU. However, given findings linking secondary traumatic stress to anxiety, depression, somatic complaints, and poor job performance in nurses working in other settings (Adriaenssens et al., 2012; Devilly et al., 2009; Figley, 1995), it is essential to explore this in NICU nurses to better understand the extent to which they experience secondary traumatic stress in their work and the associated consequences of such stress on their functioning. 


\section{Depression}

Job stress among hospital staff may adversely affect their physical or mental health, causing depressive symptoms and other health-related problems (Kikuchi, Nakaya, Ikeda, Takeda, and Nishi, 2013). Few clinical environments present more challenges to thoughtful and timely decision-making related to patient treatment than critical care (Iverson et al., 2014). Additionally, Gentry and colleagues (1972) found that ICU nurses reported more depression, hostility, and anxiety and were seen as more irritable and verbally aggressive than non-ICU nurses. Occupations involving intense work with others offer a ready environment for situations that trigger anxiety and depression, perhaps due to the increased and unavoidable social interactions ingrained in these occupations (Turnipseed, 1998). This is of particular concern in nursing where higher levels of job stress and depression may contribute to perceived nursing aggression and lower levels of patient satisfaction (Gentry et al., 1972).

Previous research has revealed that nurses are at a high risk for developing depression as a result of stressors experienced in their job (Glass, McKnight, \& Valdimarsdottir, 1993; Morrissy et al., 2013). Depressed nurses have also been found to be nearly twice as likely to experience severe job strain, defined as the experience of increased workload and staffing pressures, which is associated with heightened stress levels, absentee rates, injury rates, poor job performance, as well as chronic physical and mental conditions (Ohler et al., 2010). Furthermore, depression is associated with high rates of absenteeism and work-performance deficits which result in a multibillion-dollar annual productivity cost in the United States (Lerner \& Henke, 2008). 
Despite having a major impact on work place performance and patient care, there has been a relative absence of research investigating depression in nurses in general or in NICU nurses (Chang, Wang, Li, \& Liu, 2011; Ohler et al., 2010). However, NICU nurses are especially at risk for developing depressive symptoms because of the unique patient population, stressful interactions with parents, and vital role in protecting preterm infants compared to other nurses (White-Traut, 2015). Furthermore, while NICU nurses have been recognized as particularly susceptible to the development of increased depressive symptoms, research has yet to investigate the factors contributing to the prevalence of depression specifically in NICU nurses. However, it is critical to examine levels of depressive symptoms as well as factors that may be associated with reduced depressive symptoms in NICU nurses given the negative impact of depression on nurses as well as the patients they work with (Fujimaru et al., 2012).

\section{Burnout}

Burnout is defined as a work-related mental health impairment usually resulting from chronic stress (Awa et al., 2010; Westermann et al., 2014). High levels of burnout have implications for the well-being of professionals, the availability and retention of staff, and the maintenance of quality work environments in health services (Austin et al., 2009). Furthermore, frequent encounters with ethical and end-of-life issues are among some of the most stressful experiences for healthcare professionals and can result in burnout symptoms (Bakker et al., 2005; Teixeira et al., 2014).

Bakker and colleagues (2005) found that high job demands and limited freedom to make work place decisions are important organizational stressors influencing burnout. 
Similarly, Teixeria and colleagues (2014) demonstrated a positive association between ethical decision-making and the experience of burnout among nurses in the ICU, specifically between burnout and the need to withdraw treatments, to withhold treatments, and to proceed to a terminal sedation. Additionally, nurses who reported the highest prevalence of burnout among their colleagues were most likely to experience high levels of burnout themselves, suggesting that co-workers' behaviors and attitudes towards patients are even more important antecedents of burnout syndrome in nurses than the high demands of their occupation (Bakker et al., 2005).

The experience of vicarious trauma and burnout often overlaps in nurses (Cieslak et al., 2014). Additionally, symptoms of secondary traumatic stress and burnout syndrome are associated with a more negative outlook on the work environment, which has the potential to affect patient care (Mealer, 2009). Glass and colleagues (1993) also found that depression accounted for a substantial proportion of the variance in burnout, which they hypothesized was induced by feelings of uncontrollability. Increased levels of depression and secondary traumatic stress have also been found to be correlated with increased levels of burnout syndrome in previous studies with nurses (Cieslak et al., 2014; Glass et al., 1993). While these factors and their relationship to burnout syndrome have been studied in ICU and critical care nurses in general, limited research has investigated how these factors specifically relate to the functioning of NICU nurses.

Nurse burnout in the NICU has been widely recognized and acknowledged, but mostly unexamined by researchers. Dessy (2009) described the NICU as a fertile ground for the development of burnout syndrome because time is limited and demands are continuous. Research has found that NICU nurses had significantly higher levels of job 
stress compared to general ward nurses and reported higher levels of fatigue, depressed mood, and a tendency towards anxiety (Fujimaru, 2012). Additionally, Fujimaru (2012) found an association between higher self-perceived work-related stressors and decreased immune function because of chronic work-related stress. These findings highlight the importance of conducting more research investigating levels of burnout in NICU nurses in order to promote their mental and physical health.

\section{Proactive Coping}

Although it has been well established that nurses in general, and NICU nurses in particular, are at risk of experiencing secondary traumatic stress, depression, and burnout (Cieslak et al., 2014; Dessy, 2009; Gentry et al., 1972; Glass et al., 1993; Mealer et al., 2013; Morrissy et al., 2013), interventions targeting burnout syndrome in nurses have been mostly ineffective (Awa et al., 2010; Moody et al., 2013). However, the use of proactive coping mechanisms has been found to be associated with improved functioning in nurses suffering from burnout syndrome (Liu et al., 2015). Proactive coping has been defined as the set of cognitive and behavioral strategies used by an individual to manage the internal and external demands of stressful situations (Ding et al., 2015). Conversely, maladaptive or avoidance coping is defined as a set of emotional or behavioral strategies used to escape or disengage from a stressful situation (Welbourne, Eggerth, Hartley, Andrew, \& Sanchez, 2006). The risk of mental health problems is increased for individuals under high stress conditions who do not utilize proactive coping mechanisms (Zhao et al., 2002). Additionally, maladaptive coping strategies, such as avoidance, 
denial of the problem, and self-blame are associated with increased stress levels (Lu et al., 2015).

Problem solving and support seeking coping strategies are types of proactive coping strategies that have been found to be associated with greater job satisfaction in nurses (Welbourne, Eggerth, Hartley, Andrew, \& Sanchez, 2007). Problem solving coping strategies include both action-oriented behaviors and cognitive decision making, as well as coping strategies that focus on adjusting one's view of a stressful event (Furnham, Stewart, and Medhurst, 1996; Welbourne et al., 2007). For example, using relaxation techniques or focusing on the positive aspects of a stressful situation to decrease the negative effects of occupational stress are considered problem solving coping techniques (Skinner, Edge, Altman, and Sherwood, 2003; Welbourne et al., 2007). Support seeking coping strategies consist of problem-focused and emotion-focused support seeking (Skinner et al., 2003; Welbourne et al., 2007). For example, individuals may reach out to family, friends, or colleagues to obtain emotional support or advice. It is important to understand the difference between effective and ineffective coping strategies in the work place in order to identify targets for interventions that will benefit nurses and ultimately promote job-satisfaction and improve patient interactions.

Preventing and reducing work-related burnout is of great importance to the quality of life of those affected by, or in danger of, experiencing burnout (Awa, Plaumann, \& Walter, 2010). The use of problem solving or support seeking coping skills may serve as a protective factor for nurses at risk for burnout. For example, Chang and Chan (2015) evaluated optimism and coping in relation to burnout and found that nurses who had a problem solving coping style experienced fewer symptoms of burnout, less 
emotional exhaustion, less depersonalization, and more personal accomplishments. Additionally, previous research has found that nurses practicing problem solving or support seeking techniques report a higher sense of personal accomplishment (Ding et al., 2015) and higher levels of job satisfaction (Liu et al., 2015) as well as lower levels of strain (Laschinger et al., 2015).

The use of support seeking strategies has also been shown to decrease symptoms of traumatic stress in healthcare workers. For example, one study found that the use of social support coping strategies was associated with reduced secondary traumatic stress levels several weeks after a traumatic event took place (Shoji et al., 2014). Shoji and colleagues (2014) also found that healthcare workers who utilized support seeking coping strategies had more psychological growth and positive changes in schemas about the self and the world after experiencing trauma at work. Furthermore, support seeking coping strategies may also influence levels of burnout in nurses. The experience of secondary traumatic stress and burnout often happens simultaneously in nurses (Cieslak et al., 2014). Therefore, addressing secondary traumatic stress through increasing utilization of social support coping strategies may lower levels of burnout in nurses (Cieslak et al., 2014; Shoji et al., 2014). However, while the influence of support seeking coping strategies on levels of secondary traumatic stress has been observed in health care workers in general (Shoji et al., 2014), no research has specifically examined the influence of support seeking coping strategies on levels of secondary traumatic stress and burnout in nurses working in the NICU.

Problem solving coping strategies may also influence the association between increased depressive symptoms and higher levels of burnout (Ding et al., 2015; Glass et 
al., 1993). Research has revealed that NICU nurses, in particular, have higher levels of depressive symptoms compared to other nurses (Fujimaru et al., 2012). Additionally, the problem solving coping strategies nurses bring to their job are important predictors of levels of depression (Greenglass \& Burke, 2000). Increased depressive symptoms have also been shown to contribute to increased levels of burnout in nurses if not addressed (Glass et al., 1993). However, utilizing problem solving coping strategies has been shown to be an effective method of lowering both depressive and burnout symptoms in nurses (Chang \& Chan, 2015). Specifically, problem solving coping strategies have been demonstrated to decrease symptoms of depression in caregivers of chronically ill patients (Ferre-Grau et al., 2014). Similarly, problem solving coping strategies that promote optimistic thinking have been shown to protect nurses against depression (Chang et al., 2011). While NICU nurses have been recognized as particularly susceptible to the development of increased depressive symptoms and, consequently, increased levels of burnout, researchers have yet to investigate the effectiveness of problem solving coping strategies on depressive and burnout symptoms in NICU nurses. 


\section{CHAPTER THREE \\ STUDY AIMS AND HYPOTHESES}

\section{Study Aims}

The current study aimed to assess whether the use of problem solving or support seeking strategies moderated the relationship between secondary traumatic stress levels and burnout as well as between depressive symptomology and burnout in NICU nurses. Research has revealed that there are increased levels of depression, secondary traumatic stress, and burnout in nurses in general (Cieslak et al., 2014; Glass et al., 1993; Morrissy et al., 2013). However, limited research has evaluated how these symptoms manifest specifically in NICU nurses. Additionally, problem solving and support seeking coping strategies have been shown to be associated with lower levels of burnout and increased patient and job satisfaction in general staff nurses (Chang and Chan, 2015; Ding et al., 2015). The current study bridged these two findings by exploring the association between secondary traumatic stress levels, depressive symptomology, and burnout levels in NICU nurses as well as the potential moderating influence of problem solving or support seeking coping strategies.

\section{Study Hypotheses}

The current study examined two models evaluating the possible moderating influence of problem solving and support seeking coping strategies in NICU nurses. The first model evaluated the influence of support seeking coping strategies on the relationship between secondary traumatic stress and burnout levels in NICU nurses. The 
second model evaluated the influence of problem solving coping strategies on the relationship between depressive symptomology and burnout levels in NICU nurses.

\section{Hypothesis 1: Secondary Traumatic Stress, Burnout, and Support Seeking Coping}

The experiences of secondary traumatic stress and burnout have been observed to overlap in nurses (Cieslak et al., 2014). However, research has generally suggested that secondary traumatic stress leads to feelings of uncontrollability which then leads to burnout (Cieslak et al., 2014; Shoji et al., 2014). Support seeking coping strategies have been shown to reduce symptoms of secondary traumatic stress, and possibly burnout, in health care workers (Shoji et al., 2014). Higher levels of social support have been associated with reduced negative consequences and greater positive changes following a traumatic event (Shoji et al., 2014). Therefore, it was hypothesized that support seeking coping skills would moderate the relationship between secondary traumatic stress and burnout levels in NICU nurses, such that the positive association between secondary traumatic stress and burnout would only be significant for NICU nurses who reported low levels of support seeking coping skills (Figure 1).

\section{Hypothesis 2: Depression, Burnout, and Problem Solving Coping}

Increased depressive symptoms have also been shown to contribute to increased levels of burnout in nurses if not addressed (Glass et al., 1993). Research has revealed that problem solving coping strategies can act as protective factors against depression, and impede the development of burnout in nurses (Chang et al., 2014; Ferre-Grau et al., 2014). It was hypothesized that problem solving coping skills would moderate the 
relationship between depressive symptomology and burnout levels in NICU nurses, such that the positive association between depressive symptoms and burnout would only be significant for NICU nurses who reported low levels of problem solving coping skills (Figure 2). 


\section{CHAPTER FOUR}

\section{METHOD}

\section{Participants}

Nurses were recruited from the Loma Linda University Children's Hospital (LLUCH) NICU, which employs over 350 nurses. To be eligible for this study, the participant had to be a Registered Nurse who worked at least one shift per month in the LLUCH NICU. Participants also were required to be able to read and write in English because the measures were only available in English. A power analysis using G Power software determined at least 29 participants were needed to detect a medium sized effect (0.30) at an $80 \%$ significance level when examining a moderation model using a multiple linear regression equation. In total, 62 participants had complete data and were included in analyses; therefore, the study had acceptable statistical power.

\section{Procedure}

All nurses employed in the LLUCH NICU received a recruitment email through their work email address inviting them to complete the survey measures. This email was also posted in the break room to increase awareness of the study and ensure that all interested participants were able to participate in the study. Nurses who provided electronic informed consent completed the survey measures using the Qualtrics software program. It was estimated that measures would take 15-20 minutes to complete. Nurses were able to access the electronic surveys for a four-week period. The survey opened when the first recruitment email was sent in early January 2016. Two weeks after this email was sent, a reminder email was sent stating that the survey would be open for two 
more weeks. The survey closed four weeks after the date it opened. Individuals who completed the study measures were provided with a $\$ 5$ electronic gift card to either Amazon.com or Starbucks.

\section{Measures}

The measures chosen for this study were selected due to their strong psychometric properties and previous use in research with nurses. See Appendix A for a copy of all measures.

\section{The Professional Quality of Life Scale}

The Professional Quality of Life Scale (ProQOL) was administered to assess levels of burnout, compassion fatigue, and secondary traumatic stress. Each subscale measures separate constructs (Stamm, 2010). The ProQOL is comprised of 30 items and contains two subscales, Compassion Fatigue and Compassion Satisfaction. Each item is scored using a five-point Likert scale, with a rating of one being "never" and a rating of five being "very often." The Compassion Fatigue subscale is further broken into two components. The first, Burnout, analyzes burnout levels by looking at factors such as exhaustion, frustration, and anger. The second, Secondary Traumatic Stress, assesses symptoms associated with vicarious trauma and secondary traumatic stress, including sleep difficulties, intrusive thoughts, and avoidance behaviors. A score of 43 or below is

considered to be in the low range for each of these constructs, a score between 44 and 50 is in the medium range, and a score between 51 and 56 is in the high range. 
Previous research has found that although there is $34 \%$ shared variance between the Burnout and Secondary Traumatic Stress subscales, the two scales measure different constructs and the shared variance most likely reflects types of distress common to both conditions (Stamm, 2010). In the current study, the subscales of the ProQOL showed adequate reliability; the secondary traumatic stress subscale had a Chronbach's alpha of 0.79 and the Burnout subscale had an alpha of 0.81 .

\section{The Center for Epidemiological Studies Depression Scale.}

The Center for Epidemiological Studies Depression Scale (CES-D) was administered to assess depressive symptoms. The CES-D contains 20 items that form six scales, including depressed mood, feelings of guilt and worthlessness, feelings of helplessness and hopelessness, psychomotor retardation, loss of appetite, and sleep disturbance (Radloff, 1977a). Each item is responded to using a scale ranging from zero to three, with zero being "rarely" or "none of the time" and three being "all of the time." Scores for items $4,8,12$, and 16 are reverse scored before calculating a total score. A score of sixteen or greater is considered to indicate a clinical level of depressive symptomology (Radloff, 1977b). The CES-D demonstrated strong reliability in the current study, with a Chronbach's alpha of 0.89 .

\section{The Brief COPE}

The Brief COPE Inventory was administered to assess the use of proactive coping skills. The Brief COPE is a condensed version of the 60-item COPE Inventory (Carver, 1997). The brief COPE includes 28 items that measure 14 different coping reactions. 
Each item is responded to using a scale ranging from one to four, with one being "I haven't been doing this at all" and four being "I've been doing this a lot." The Brief COPE yields three subscales: Problem Solving coping strategies, Avoidance coping strategies, and Support Seeking coping strategies (Carver, 1997). Each subscale demonstrated acceptable reliability when used in the current study; the Problem Solving coping strategies subscale had a Chronbach's alpha of 0.89 and the Support Seeking coping strategies subscale had an alpha of 0.87 .

\section{Statistical Analysis}

Prior to analyses, Pearson and Bivariate correlations between demographic variables (i.e., age, number of times attending a religious service per month, number of years of nursing experience, gender, race, and martial status) and the independent and dependent variables (secondary traumatic stress, depression, burnout, problem solving, and support seeking coping strategies) were examined. Pearson and Spearman's Rho correlations were computed to assess relationships between demographic variables and the independent and dependent variables. Given that only one male responded to the survey, it was decided to not include gender in analyses. There were no significant correlations between any demographic variables and the independent and dependent variables (Tables 1 and 2). Therefore, no demographic variables were controlled for in the regression equations. 
Table 1. Pearson Correlations

\begin{tabular}{lcccccccc}
\hline & 1 & 2 & 3 & 4 & 5 & 6 & 7 & 8 \\
\hline 1. Support Seeking & & $0.73^{* *}$ & $0.30^{*}$ & $0.40^{* *}$ & $0.28^{*}$ & -0.02 & 0 & 0.16 \\
2. Problem Solving & $0.73^{* *}$ & & 0.38 & $0.46^{* *}$ & $0.34^{* *}$ & -0.02 & 0.05 & 0.2 \\
3. Burnout & $0.29^{*}$ & $0.38^{* *}$ & & $0.51^{* *}$ & $0.54^{* *}$ & -0.02 & 0.14 & 0.13 \\
4. Secondary Traumatic Stress & $0.40^{* *}$ & $0.46^{* *}$ & $0.51^{* *}$ & & $0.42^{* *}$ & -0.03 & 0.05 & 0.12 \\
5. Depression & $0.28^{*}$ & $0.34^{* *}$ & $0.54^{* *}$ & $0.42^{* *}$ & & -0.08 & -0.07 & -0.11 \\
6. Age & -0.02 & -0.02 & -0.02 & -0.03 & -0.08 & & $0.85^{* *}$ & 0.2 \\
7. Religious Attendance per Month & 0 & 0.05 & 0.14 & 0.05 & -0.07 & 0.85 & & 0.18 \\
8. Years of Nursing Experience & 0.16 & 0.2 & 0.13 & 0.12 & -0.11 & 0.2 & 0.18 & \\
\hline
\end{tabular}
$* p<.05, * * p<.01$ 
Table 2. Nonparametric Spearman's Rho Correlations

\begin{tabular}{|c|c|c|c|c|c|c|c|}
\hline & 1 & 2 & 3 & 4 & 5 & 6 & 7 \\
\hline 1. Support Seeking & & $0.70 * *$ & $\begin{array}{l}0.32 * \\
0.41 *\end{array}$ & $0.39 * *$ & $0.32 *$ & -0.06 & 0.15 \\
\hline 2. Problem Solving & $0.70 * *$ & & $*$ & $0.47 * *$ & $0.36^{* *}$ & 0.03 & 0.19 \\
\hline 3. Burnout & $0.32 *$ & $0.41 * *$ & $0.52 *$ & $0.52 * *$ & $0.60 * *$ & -0.24 & 0.06 \\
\hline 4. Secondary Traumatic Stress & $0.39 * *$ & $0.47 * *$ & $\begin{array}{c}* \\
0.60 *\end{array}$ & & $0.47 * *$ & -0.002 & 0.05 \\
\hline 5. Depression & $0.32 *$ & $0.36 * *$ & $*$ & $0.47 *$ & & -0.16 & 0.05 \\
\hline 6. Martial Status & -0.06 & 0.03 & -0.24 & -0.002 & -0.16 & & -0.17 \\
\hline 7. Race & 0.15 & 0.19 & 0.06 & 0.05 & 0.05 & -0.17 & \\
\hline
\end{tabular}

$* p<.05, * * p<.01$ 
Multiple linear regression and a hierarchical stepwise technique was used for the moderator analyses, using the guidelines of Baron and Kenny (1986) and the statistical software IBM SPSS Statistics 22. The variables were entered in a stepwise procedure (independent variable, moderator variable, interaction term). The interaction term was created by multiplying the independent variable and the moderator variable after both variables were centered (Baron \& Kenny, 1986). A significant interaction term indicated that the moderation was supported. Significant interactions were probed using the guidelines of Baron and Kenny (1986) to describe the moderator effect.

For Hypothesis 1, the independent variable of the regression equation was secondary traumatic stress levels (i.e., the Secondary Traumatic Stress subscale from the ProQOL), the moderator variable was utilization of social support coping skills (i.e., Support Seeking subscale from the Brief COPE), and the interaction term was secondary traumatic stress levels X support seeking coping skills. The dependent variable was level of burnout (i.e., Burnout scale from the ProQOL).

For Hypothesis 2, the independent variable of the regression equation was depressive symptomology (i.e., the total score from the CES-D), the moderator variable was utilization of problem solving coping skills (i.e., Problem Solving subscale from the Brief COPE), and the interaction variable was depressive symptomology $\mathrm{X}$ problem solving coping skills. The dependent variable was burnout levels (i.e., Burnout scale from the ProQOL). 


\section{CHAPTER FIVE}

\section{RESULTS}

There were 67 individuals that began the survey and 62 individuals completed all measures; thus, the final dataset included 62 participants. Given that there are 357 nurses employed in the NICU, the response rate was $17 \%$ (62/357). Due to the fact that participants were provided with the option "prefer not to respond" for all items, some individuals had missing data. Specifically, one person did not have complete data on the CES-D, three people did not have complete data on the Brief COPE, and five people did not have complete data for the ProQOL. Given the small sample size, the decision was made to use multiple imputation rather than listwise deletion to address missing data. Missing data were imputed using SPSS's Multiple Imputation technique with five imputations (IBM, 2012), and the Pooled imputation was used for all results.

Table 3 provides a list of relevant demographic information. The majority of participants identified as White (64.5\%) and female (98.4\%) with a mean age of 41.65 years $(S D=13.05)$. Participants reported a mean of $15.32(S D=13.39)$ years of nursing experience, with a mean of $11.63(S D=11.10)$ years working in the LLUCH NICU. Approximately $85 \%$ of nurses classified themselves as a "staff nurse" and the majority of participants had obtained a BSN degree $(66.1 \%)$. Approximately $59 \%$ of participants were married and the majority identified their religious affiliation as some denomination of the Christian faith (35.5\% Christian, 32.2\% Seventh Day Adventist, 12.9\% Catholic, 6.4\% Baptist, and 1.6\% Lutheran). The average number of times participants reported attending a religious service per month was $2.95(S D=2.64)$. 
Table 3. Demographics of the Current Sample

\begin{tabular}{|c|c|c|}
\hline Demographic & $\%$ & $N$ \\
\hline \multicolumn{3}{|l|}{ Sex } \\
\hline Female & 96.8 & 60 \\
\hline Male & 1.6 & 1 \\
\hline Prefer Not to Respond & 1.6 & 1 \\
\hline \multicolumn{3}{|l|}{ Race } \\
\hline Caucasian & 64.5 & 40 \\
\hline Asian & 19.4 & 12 \\
\hline Hispanic & 8,1 & 5 \\
\hline Multiracial & 3.2 & 2 \\
\hline \multicolumn{3}{|l|}{ Position Title } \\
\hline Staff Nurse & 85.5 & 53 \\
\hline Charge Nurse & 4.8 & 3 \\
\hline Manager/Supervisor/Director & 3.2 & 2 \\
\hline Clinical Nurse Specialist & 1.6 & 1 \\
\hline Nurse Educator & 1.6 & 1 \\
\hline Other & 3.2 & 2 \\
\hline \multicolumn{3}{|l|}{ Martial Status } \\
\hline Married & 59.7 & 37 \\
\hline Single & 22.6 & 14 \\
\hline Single, in a relationship & 9.7 & 6 \\
\hline Divorced & 4.8 & 3 \\
\hline Prefer Not to Respond & 3.2 & 2 \\
\hline \multicolumn{3}{|l|}{ Highest Degree } \\
\hline $\mathrm{BSN}$ & 66.1 & 41 \\
\hline $\mathrm{AD}$ & 25.8 & 16 \\
\hline MS/MSN & 4.8 & 3 \\
\hline Other Diploma & 3.2 & 2 \\
\hline \multicolumn{3}{|l|}{ Religious Affiliation } \\
\hline Christian & 35.5 & 22 \\
\hline SDA & 32.2 & 20 \\
\hline Catholic & 12.9 & 8 \\
\hline Baptist & 6.4 & 4 \\
\hline Buddhist & 1.6 & 1 \\
\hline Lutheran & 1.6 & 1 \\
\hline None & 9.7 & 6 \\
\hline
\end{tabular}


In terms of clinical symptomatology, the majority of respondents reported nonclinically elevated levels of symptoms of depression, secondary traumatic stress, and burnout. NICU nurses reported an average depressive symptomology rating of 10.67 (SD $=8.06$ ), which does not indicate clinically significant levels of depressive symptomology. Only $22 \%$ of participants reported depressive symptomatology in the clinically elevated range (i.e., a total score of 16 or greater). The average secondary traumatic stress symptomology reported by NICU nurses was $21.60(S D=4.80)$, which indicates lower levels of secondary traumatic stress symptoms. Overall, $100 \%$ of participants reported secondary traumatic stress symptoms in the low range (i.e., a score of 43 or below). The average burnout symptomology reported by NICU nurses was $20.15(S D=5.01)$, which indicates low levels of burnout symptoms. Overall, $100 \%$ of participants reported burnout symptoms in the low range (i.e., a score of 43 or below). The total problem solving coping skills score was comprised of eight items, with the highest possible score being 32 and the lowest possible score being eight. The mean utilization of problem solving coping strategies reported by NICU nurses was $18.95(S D=6.09)$, which indicates the average rating for utilization of problem solving coping skills fell between "I've been doing this a little bit" and "I've been doing this a medium amount." The total support seeking coping skills score was comprised of four items with the highest possible score being 16 and the lowest possible score being a four. The average utilization of support seeking coping skills was $9.95(S D=3.44)$, which indicates the average rating of utilization of support seeking coping skills was "I've been doing this a lot." 


\section{Secondary Traumatic Stress and Support Seeking}

To test Hypothesis 1 (secondary traumatic stress, support seeking, and burnout symptoms), a hierarchical multiple regression analysis was conducted. Regression findings for Hypothesis 1 are presented in Table 4. Analyses revealed a significant main effect of secondary traumatic stress $(B=0.55, \beta=0.54, t(58)=4.32, p<.01)$ as well as a significant interaction between secondary traumatic stress and support seeking coping skills $(B=-0.07, \beta=-0.24, t(58)=-2.03, p<.05)$. Therefore, Hypothesis 1 was supported because the relationship between secondary traumatic stress and burnout symptoms in NICU nurses depended on whether they engaged in high versus low levels of support seeking coping strategies. The overall $R^{2}$ of the model was 0.32 , indicating that the complete model accounted for $32 \%$ of the variance (Table 4).

Given the significant interaction term, post-hoc analyses were conducted to determine the nature of the interaction. To probe this interaction, the recommendations by Holmbeck (2002) were followed; two variables were calculated to represent participants one standard deviation above (i.e. high support seeking) and below (i.e. low support seeking) the mean for the moderating variable, support seeking. Analyses were run in which newly computed high and low support seeking variables were separately entered into the regression equation replacing the original support seeking variables. Simple slope tests revealed that the amount of secondary traumatic stress reported was significantly associated with burnout symptoms for those with high levels of support seeking, $B=$ $0.80, \beta=0.78, t(58)=3.98, p<.01$, as well as for those with low support seeking, $B=$ $0.31, \beta=0.30, t(58)=2.03, p<.05$ (Table 4). Although the finding was significant for both the low and high support conditions, the effect was larger in the high support 
condition, suggesting that those who reported higher levels of support seeking coping skills also reported higher levels of stress. 


\begin{tabular}{|c|c|c|}
\hline $\begin{array}{c}\text { Secondary } \\
\text { Traumatic } \\
\text { Stress } \\
\text { Symptoms }\end{array}$ & $0.55^{*}$ & $\begin{array}{c}\text { Burnout } \\
\text { Symptoms }\end{array}$ \\
\hline
\end{tabular}

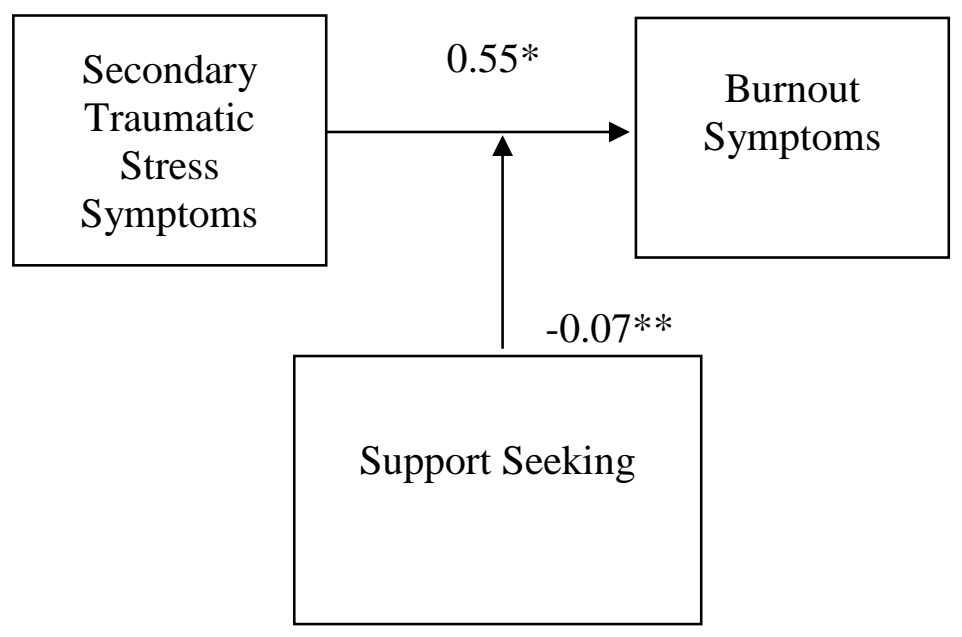

Figure 1. Path diagram for moderation analysis evaluating social support coping strategies as a moderator of the relationship between secondary traumatic stress symptoms and burnout symptoms in NICU nurses. 
Table. 4 Regression and Post-hoc Findings for Secondary Traumatic Stress, Depression, and Traumatic Stress and Support Seeking Interaction

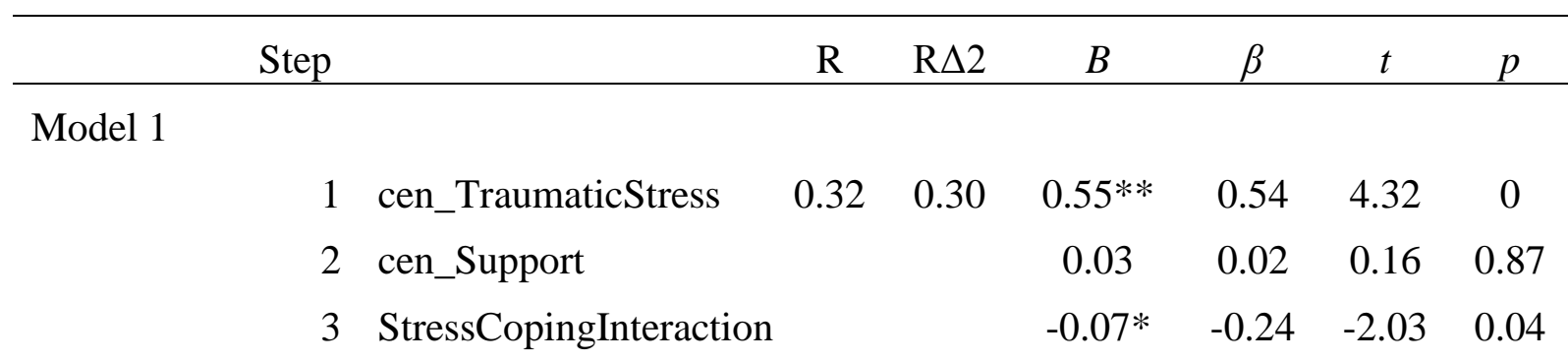

Model 1

Interaction

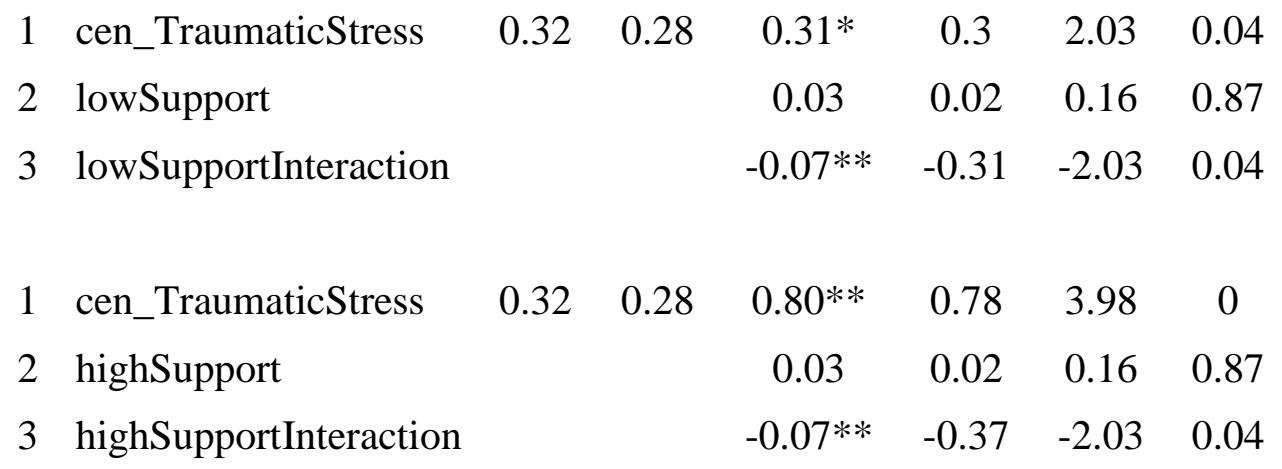

Model 2

\begin{tabular}{|c|c|c|c|c|c|}
\hline 1 & cen_Depression & $0.29 *$ & 0.47 & 3.98 & 0 \\
\hline & cen_CogProbSolving & 0.18 & 0.21 & 1.87 & 0.06 \\
\hline & DepressionCopingInteraction & -0.003 & -0.03 & -0.24 & 0.81 \\
\hline
\end{tabular}

$* p<.05, * * p<.01$ 


\section{Depression and Problem Solving}

To test Hypothesis 2 (depressive symptoms, problem solving coping, and burnout), a hierarchical multiple regression analysis was conducted. Regression findings for Hypothesis 2 are presented in Table 4. Our analysis revealed a significant main effect of depressive symptoms $(B=0.29, \beta=0.47, t(58)=3.98, p<.01)$. The main effect of problem solving coping strategies was not significant $(B=0.18, \beta=0.22, p=.06)$. The interaction term was also not significant $(B=-0.03, \beta=-0.03, p=0.8)$. The overall $R^{2}$ of the model was 0.33 , indicating that the complete model accounted for $33 \%$ of the variance (Table 4). Therefore, contrary to our hypothesis, the utilization of problem solving coping skills did not moderate the relationship between depressive symptoms and burnout symptoms in NICU nurses. However, the significant main effect for depressive symptoms suggests that nurses with higher levels of depressive symptoms are more likely to report higher levels of burnout. 

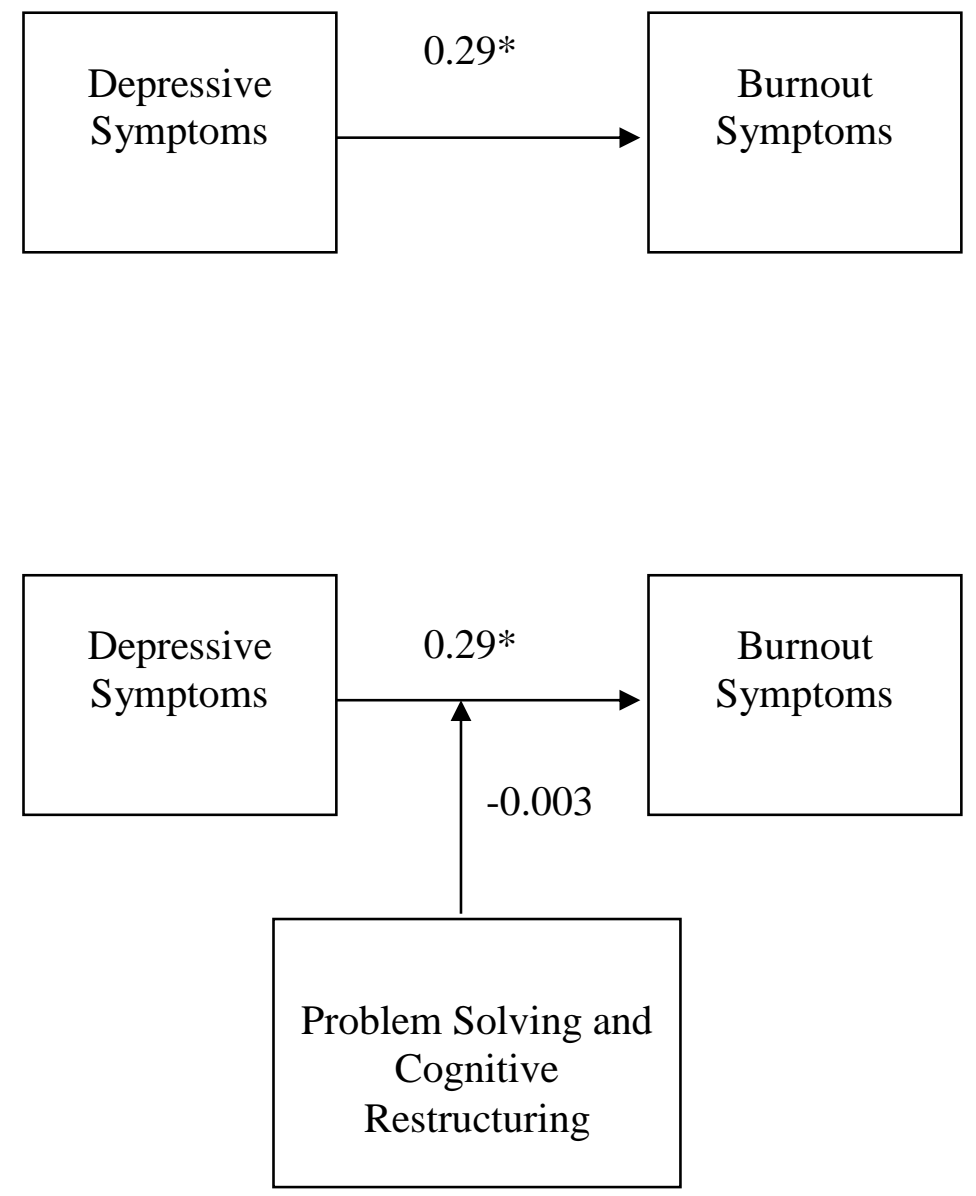

Figure 2. Path diagram for moderation analysis evaluating problem solving coping strategies as a moderator of the relationship between depressive symptomology and burnout symptoms levels in NICU nurses. 


\section{CHAPTER SIX}

\section{DISCUSSION}

The aim for the current study was to examine the extent to which support seeking and problem solving coping skills moderate the relationship between secondary traumatic stress symptoms, depressive symptoms, and burnout symptoms in NICU nurses. The current study used two models to evaluate the potential moderating influence of support seeking and problem solving coping strategies in NICU nurses. With the first model (Hypothesis 1), it was hypothesized that support seeking coping skills would moderate the relationship between secondary traumatic stress and burnout levels in NICU nurses. With the second model (Hypothesis 2), it was hypothesized that problem solving coping skills would moderate the relationship between depressive symptomology and burnout levels in NICU nurses.

Hypothesis 1 was partially supported. A significant interaction was found; support seeking coping skills significantly moderated the relationship between secondary traumatic stress symptoms and burnout symptoms in NICU nurses. However, after conducting a post-hoc analysis to probe the interaction, results indicated that the effect was larger in NICU nurses engaging in high levels of support seeking coping skills. In other words, NICU nurses who reported higher levels of secondary traumatic stress symptoms and who reported that they engaged in higher levels of support seeking coping skills also reported higher levels of burnout when compared with nurses who reported lower levels of support seeking coping.

The unexpected finding regarding the moderating effect of social support may be explained by the relationship between perceived and received support. Some researchers 
have argued that perceived support and received support are separate constructs that may be associated with different psychosocial and health outcomes (Uchino, 2009). Received support is defined as the quantity of supportive behaviors received by an individual (Haber, Cohen, Lucas, \& Baltes, 2007). Perceived support is defined as a combination of an individuals' satisfaction with support and the availability of support to them (Sarason, Sarason, \& Pierce, 1990). Perceived support has been found to be consistently associated with positive health outcomes in previous research (Barrera, 2000; Melrose, Brown, \& Wood, 2014). On the other hand, previous research has found an inconsistent relationship between received support and health, with some studies finding non-significant results and others finding negative associations, such as those found in the current study (Bolger \& Amarel, 2007). Furthermore, some studies have found that received support is actually associated with greater reported levels of stress (Barrera, 1986). The current study did not differentiate between perceived and received support, and it is likely that both concepts were measured. Specific social support questions included, "I get emotional support from others," which evaluates emotional support that can be either perceived or received, and "I get help and advice from other people," which strictly evaluates received support.

In addition to differences in outcomes associated with perceived versus received support, the counterintuitive finding for social support in this study may be related to possible shared environmental factors of NICU nurses. Some researchers have hypothesized that people interacting with someone undergoing a stressful event may feel anxious about these interactions and provide unhelpful support because they do not want to say anything that would upset the individual (Lehman, Ellard, \& Wortman, 1986; Uchino, 2009). Therefore, it is possible that NICU nurses with higher levels of secondary 
traumatic stress are engaging in higher levels of support seeking from their coworkers, which is causing their coworkers to experience more stress and provide unhelpful forms of support. This cycle may ultimately result in higher levels of secondary traumatic stress and burnout symptoms in NICU nurses who engage in higher levels of support seeking at work.

Finally, it is possible that those who exhibit high levels of traumatic stress and burnout symptoms seek high levels of social support in an attempt to cope with their stress. Therefore, the finding that those who reported high levels of traumatic stress and social support also reported high levels of burnout may be indicative of attempts to cope with traumatic stress and burnout symptoms (Lehman et al., 1986; Uchino, 2009). In other words, individuals in the study who experienced greater traumatic stress may have been more likely to seek out social support than those who experienced less traumatic stress. Given that this was a cross-sectional study, the timing of symptoms and coping cannot be inferred. Longitudinal research is needed to better understand the relationship between social support, traumatic stress, and coping as well as the timing of coping behavior and symptomatology.

Hypothesis 2 was not supported because the interaction term was not significant, indicating that problem solving coping did not moderate the relationship between depressive symptoms and burnout. However, analyses revealed a significant main effect for depression, suggesting that nurses with higher levels of depressive symptoms also reported higher levels of burnout symptoms. The findings for this main effect support those of previous research that has linked increased depressive symptoms in nurses with an increased likelihood of developing burnout symptoms (Cieslak et al., 2014; Glass et 
al., 1993). Furthermore, given that only $22 \%$ of nurses in our study reported clinically elevated levels of depressive symptoms, these results demonstrate that even sub-clinical levels of depressive symptoms are associated with higher levels of burnout symptoms. However, the utilization of problem solving coping skills did not moderate the relationship between depressive symptoms and burnout symptoms in NICU nurses.

The findings for Hypothesis 2 contradict those of previous research which have demonstrated that utilizing problem solving coping skills is an effective method for lowering both depressive and burnout symptoms in nurses (Chang \& Chan, 2015). One possible reason for these unexpected findings could be due to the nature of the work done by NICU nurses. NICU nurses often face continuous demands from the parents of their young patients, and nurses may experience stressors that are not easily solved (e.g., parent who is distressed about an infant that is dying, parent who is depressed about family financial stressors). Previous research has emphasized that NICU nurses are in a key position to share information with families and they are often the first members of the treatment team to communicate with parents about staffing complaints, changes in treatment plans, and answering parent questions or providing feedback about a patient's progress (Griffin, 2006). Therefore, interacting with NICU parents has become a stressful task that further influences depressive symptoms (White-Traut, 2015). Similarly, mothers of infants in the NICU often struggle with their inability to comfort their child, which has been shown to not only increase the stress of the mother but to also increase the frequency of stressful and negative interactions between NICU staff and parents (Griffin, 2006). Therefore, it is possible that problem solving coping strategies are less useful for nurses who are experiencing depressive symptoms and burnout as a result of stressors 
that do not have an apparent solution such as stressful interactions with parents or other complex problems related to work in the NICU.

Finally, the discrepancies between our results and previous studies may be explained by the distribution of depressive and burnout symptoms reported by participants in the current study. As mentioned above, only $22 \%$ of nurses reported clinically elevated levels of depressive symptoms and $100 \%$ of nurses reported low levels of burnout symptoms. Therefore, it is possible that there was not enough variance to detect a significant moderating effect for problem solving coping skills.

\section{Strengths}

The current study had a number of strengths. First, participants were sampled from a large NICU and therefore the current study obtained a sufficient sample size for adequate statistical power. Furthermore, the measures that were selected for the current study were psychometrically sound, with all independent and dependent variable subscale alphas falling above 0.70 , which indicates good internal consistency. The current study also strengthens the current literature regarding NICU nurse mental health and well-being by not only examining levels of secondary traumatic stress, depressive, and burnout symptoms in NICU nurses, but also evaluating the possible benefits of specific coping strategies. This information is beneficial because it can be used to inform the development of programs that could promote the well-being and coping of nurses experiencing mental health difficulties or burnout. 


\section{Limitations}

Although this study had many strengths, it also had some limitations. First, although efforts were made to engage all nurses in this large NICU, the response rate was only $17 \%$. Therefore, these results may not be generalizable to all nurses working in the LLUCH NICU or to the broader population of NICU nurses across the country. Second, results indicate that the models tested in the current study only accounted for $30-35 \%$ of the variance, indicating that there are additional variables that may be contributing to the levels of burnout symptoms in NICU nurses. However, all theoretically identified covariates were examined in the current study prior to analyses and no significant correlations between covariates and the independent and dependent variables were found. Third, the majority of participants did not report elevated levels of secondary traumatic stress, depressive, and burnout symptoms. In the current sample, $100 \%$ of participants reported low levels (below the $25^{\text {th }}$ percentile) of secondary traumatic stress and burnout symptoms and $78 \%$ reported non-clinical levels of depressive symptoms (i.e., below a score of 16). Although nurses were assured that their responses would be kept confidential, it is possible that nurses did not feel comfortable providing truthful responses given that they received the survey invitation through their work email. Additionally, burnout is often characterized by increased stress levels, lower levels of productivity, and fatigue (Austin et al., 2009; Fujimaru, 2012). Therefore, it is possible that those nurses who were experiencing burnout were in fact too burned out to expend the energy and time needed to participate in the current study. Finally, nurses who completed the measures were required to find the time and space in their schedule to complete the measures. Therefore, additional efforts to provide protected time and space 
to complete the survey measures (e.g., an additional 20 minute break during a nurse's work shift) may have resulted in a higher response rate and may have yielded a more diverse sample that varied in their symptomatology.

\section{Future Directions}

To the best of our knowledge, this is the first study conducted to examine the moderating effect of coping skills on the relationship between secondary traumatic stress symptoms, depressive symptoms, and burnout symptoms in NICU nurses. Although this study was an important first step, additional research is needed to better understand how to promote coping and reduce burnout in this at risk population of nurses. Future research should aim to identify both risk and protective factors that could be possible targets of preventive interventions that aim to reduce burnout and improve mental health in nurses who experience high levels of stress in the context of their job in the NICU. For example, a structured setting during each NICU shift in which a professional facilitator provides support in the form of teaching relaxation skills or mindfulness for NICU nurses may be

more beneficial in order to ensure that NICU nurses are coping effectively with stressors. More research is needed to explore how the use of relaxation skills, such as mindfulness, may facilitate a nurse's ability to cope with the stress that is inevitable in NICU environment. Additionally, longitudinal studies are needed to examine the effects of proactive coping and social support on NICU nurse emotional functioning over time to better understand the timing of symptoms of traumatic stress, depression, and burnout and the possible protective effects of coping strategies. Finally, research that is more inclusive of all nurses working in the NICU is needed to better understand the strengths 
and needs of nurses from various backgrounds and with varied levels of stress, depression, and burnout symptoms.

NICU nurses play a critical role in caring for vulnerable newborns, making their mental functioning essential to the developmental success of these infants. Continued research examining traumatic stress, depressive, and burnout symptoms as well as coping in NICU nurses is vital to foster a healthy work environment and promote the mental health of all NICU nurses so that they can provide the best possible intervention to the vulnerable infants they work with. 


\section{REFERENCES}

Adriaenssens, J., de Gucht, V., \& Maes, S. (2012). The impact of traumatic events on emergency room nurses: Findings from a questionnaire survey. International Journal Of Nursing Studies, 49(11), 1411-1422.

doi:10.1016/j.ijnurstu.2012.07.003

Anderson, J. (2008). Depression, stress, and work: How occupation can affect mental health. Journal of Controversial Medical Claims, 15(1), 6-15.

Austin, W., Goble, E., Leier, B., \& Byrne, P. (2009). Compassion fatigue: The experience of nurses. Ethics And Social Welfare, 3(2), 195-214. doi:10.1080/17496530902951988

Awa, W. L., Plaumann, M., \& Walter, U. (2010). Burnout prevention: a review of intervention programs. Patient Education and Counseling, 78(2), 184-90. doi:10.1016/j.pec.2009.04.008

Bakker, A. B., Le Blanc, P. M., \& Schaufeli, W. B. (2005). Burnout contagion among intensive care nurses. Journal Of Advanced Nursing, 51(3), 276-287. doi:10.1111/j.1365-2648.2005.03494.x

Baron, R. M., \& Kenny, D. A. (1986). The moderator-mediator variable distinction in social psychological research: Conceptual, strategic, and statistical considerations. Journal Of Personality And Social Psychology, 51(6), 1173-1182. doi:10.1037/0022-3514.51.6.1173

Barrera, M. (1986). Distinctions between social support concepts, measures, and models. American Journal of Community Psy- chology, 14, 413-445.

Barrera, M. (2000). Social support research in community psychology. In J. Rappaport \& E. Seidman (Eds.), Handbook of community psychology (pp. 215-245). New York: Kluwer Academic/Plenum.

Beal, J. A., \& Quinn, M. (2002). The nurse practitioner role in the NICU as perceived by parents. MCN: The American Journal Of Maternal/Child Nursing, 27(3), 183188. doi:10.1097/00005721-200205000-00011

Beck, C. T. (2011). Secondary traumatic stress in nurses: A systematic review. Archives Of Psychiatric Nursing, 25(1), 1-10. doi:10.1016/j.apnu.2010.05.005

Bolger, N., \& Amarel, D. (2007). Effects of social support visibility on adjustment to stress: Experimental evidence. Journal of Person- ality and Social Psychology, 92, $458-475$.

Carver, C. S. (1997). Brief COPE Inventory. Psyctests, doi:10.1037/t04102-000 
Chang, Y., \& Chan, H.-J. (2015). Optimism and proactive coping in relation to burnout among nurses. Journal of Nursing Management, 23(3), 401-8. doi:10.1111/jonm. 12148

Chang, Y., Wang, P., Li, H., \& Liu, Y. (2011). Relations among depression, selfefficacy and optimism in a sample of nurses in Taiwan. Journal Of Nursing Management, 19(6), 769-776. doi:10.1111/j.1365-2834.2010.01180.x

Chiang, Y., \& Chang, Y. (2012). Stress, depression, and intention to leave among nurses in different medical units: Implications for healthcare management/nursing practice. Health Policy, 108(2-3), 149-157. doi:10.1016/j.healthpol.2012.08.027

Cieslak, R., Shoji, K., Douglas, A., Melville, E., Luszczynska, A., \& Benight, C. C. (2014). A meta-analysis of the relationship between job burnout and secondary traumatic stress among workers with indirect exposure to trauma. Psychological Services, 11(1), 75-86. doi:10.1037/a0033798

Clark, M., \& Gioro, S. (1998). Nurses, indirect trauma, and prevention. Image: Journal of Nursing Scholarship, 30(1), 85-87.

Crabbe, J., Bowley, D., Boffard, K., Alexander, D., Klein, S. (2004) Are health professionals getting caught in the crossfire? The personal implications of caring for trauma victims. Emergency Medicine Journal.21:568-572.

Dane, B. \& Chachkes, E. (2001). The cost of caring for patients with an illness: Contagion to the social worker. Social Work in Health Care, 3, 31-51.

Dessy, E. (2009). Effective communication in difficult situations: Preventing stress and burnout in the NICU. Early Human Development, 85(10, Suppl), S39-S41. doi:10.1016/j.earlhumdev.2009.08.012

Devilly, G. J., Wright, R., \& Varker, T. (2009). Vicarious trauma, secondary traumatic stress or simply burnout? Effect of trauma therapy on mental health professionals. Australian And New Zealand Journal Of Psychiatry, 43(4), 373-385. doi:10.1080/00048670902721079

Ding, Y., Yang, Y., Yang, X., Zhang, T., Qiu, X., He, X., \& ... Sui, H. (2015). The mediating role of coping style in the relationship between psychological capital and burnout among Chinese nurses. Plos ONE, 10(4)

Ferré- Grau, C., Sevilla- Casado, M., Lleixá- Fortuño, M., Aparicio- Casals, M. R., Cid- Buera, D., Rodero- Sanchez, V., \& Vives- Relats, C. (2014). Effectiveness of problem- solving technique in caring for family caregivers: A clinical trial study in an urban area of Catalonia (Spain). Journal Of Clinical Nursing, 23(1-2), 288-295. doi:10.1111/jocn.12485 
Figley, C. R. (1995). Compassion fatigue: Secondary traumatic stress disorders from treating the traumatized. New York: Brunner/Mazel.

Fujimaru, C., Okamura, H., Kawasaki, M., Kakuma, T., Yoshii, C., \& Matsuishi, T. (2012). Self- perceived work- related stress and its relation to salivary IgA, cortisol and 3- methoxy- 4- hydroxyphenyl glycol levels among neonatal intensive care nurses. Stress And Health: Journal Of The International Society For The Investigation Of Stress, 28(2), 171-174. doi:10.1002/smi.1414

Furnham, A., Stewart, S., \& Medhurst, S. (1996). Occupational attributional style, attitudes to work and perceived social consensus. Polish Psychological Bulletin, 27(2), 153-166

Gentry, W., Foster, S., Froehling, S (1972). Psychologic Response to Situation Stress in Intensive and Non-intensive Nursing. Heart Lung, 3(1): 793-796.

Glass, D. C., McKnight, J. D., \& Valdimarsdottir, H. (1993). Depression, burnout, and perceptions of control in hospital nurses. Journal Of Consulting And Clinical Psychology, 61(1), 147-155. doi:10.1037/0022-006X.61.1.147

Greenglass, E. R., \& Burke, R. J. (2000). Hospital downsizing, individual resources, and occupational stressors in nurses. Anxiety, Stress \& Coping: An International Journal, 13(4), 371-390. doi:10.1080/10615800008248342

Griffin, T. (2006). Family-centered care in the NICU. The Journal Of Perinatal \& Neonatal Nursing, 20(1), 98-102.

Haber, M. G., Cohen, J. L., Lucas, T., \& Baltes, B. B. (2007). The relationship between self-reported received and perceived social support: A meta-analytic review. American Journal Of Community Psychology, 39(1-2), 133-144. doi:10.1007/s10464-007-9100-9

Hall, S. L. (2016). Frequently Asked Questions About Prematurity. For the Love of Babies. Retreived from http://www.suehallmd.com/aboutprematurebabies.html

Harris, R. B. (1989). Reviewing nursing stress according to a proposed coping-adaption framework. Advances In Nursing Science, 11(2), 12-28.

Holmbeck, G. N. (2002). Post-hoc probing of significant moderational and mediational effects in studies of pediatric populations. Journal Of Pediatric Psychology, 27(1), 87-96. doi:10.1093/jpepsy/27.1.87

Hunsaker, S., Chen, H., Maughan, D., \& Heaston, S. (2015). Factors that influence the development of compassion fatigue, burnout, and compassion satisfaction in emergency department nurses. Journal Of Nursing Scholarship, 47(2), 186-194. doi:10.1111/jnu.12122 
IBM. (2012). IBM SPSS Statistics for Windows (Version 21.0). Armonk, NY: IBM Corporation.

Iverson, E., Celious, A., Kennedy, C. R., Shehane, E., Eastman, A., Warren, V., \& Freeman, B. D. (2014). Factors affecting stress experienced by surrogate decision makers for critically ill patients: Implications for nursing practice. Intensive And Critical Care Nursing, 30(2), 77-85. doi:10.1016/j.iccn.2013.08.008

Kain, V. J. (2007). Moral distress and providing care to dying babies in neonatal nursing. International Journal of Pallia- tive Nursing, 13(5), 242-247

Keenan, P., \& Royle, L. (2007). Vicarious trauma and first responders: A case study utilizing eye movement desensitization and reprocessing (EMDR) as the primary treatment modality. International Journal Of Emergency Mental Health, 9(4), 291-298.

Kikuchi, Y., Nakaya, M., Ikeda, M., Takeda, M., \& Nishi, M. (2013). Job stress and temperaments in female nurses. Occupational Medicine, 63(2), 123-128. doi:10.1093/occmed/kqs212

Klein, S. M. (2009). Moral distress in pediatric palliative care: A case study. Journal of Pain and Symptom Management, 38(1), 157-160.

doi:10.1016/j.jpainsymman.2009.04.014

Laschinger, H. S., Borgogni, L., Consiglio, C., \& Read, E. (2015). The effects of authentic leadership, six areas of worklife, and occupational coping self-efficacy on new graduate nurses' burnout and mental health: A cross-sectional study. International Journal Of Nursing Studies, 52(6), 1080-1089. doi:10.1016/j.ijnurstu.2015.03.002

Lehman, D.R., Ellard, J.H., \& Wortman, C.B. (1986). Social support for the bereaved: Recipients' and providers' perspectives on what is helpful. Journal of Consulting and Clinical Psychology, 54, 438-446.

Lerner, D., \& Henke, R. M. (2008). What does research tell us about depression, job performance and work productivity? Journal of Occupational and Environmental Medicine, 50, 401-410.

Liu, Y., While, A., Li, S., \& Ye, W. (2015). Job satisfaction and work related variables in Chinese cardiac critical care nurses. Journal Of Nursing Management, 23(4), 487497. doi:10.1111/jonm.12161

Lu, D., Sun, N., Hong, S., Fan, Y., Kong, F., \& Li, Q. (2015). Occupational stress and coping strategies among emergency department nurses of China. Archives Of Psychiatric Nursing, 29(4), 208-212. doi:10.1016/j.apnu.2014.11.00 
Mallett, K., Price, J. H., Jurs, S. G., \& Slenker, S. (1991). Relationships among burnout, death anxiety, and social support in hospice and critical care nurses.

Psychological Reports, 68(3, Pt 2), 1347-1359. doi:10.2466/PR0.68.4.1347-1359

Mealer, M., Burnham, E. L., Goode, C. J., Rothbaum, B., \& Moss, M. (2009). The prevalence and impact of post traumatic stress disorder and burnout syndrome in nurses. Depression And Anxiety, 26(12), 1118-1126. doi:10.1002/da.20631

Mealer, M., Jones, J., Newman, J., McFann, K. K., Rothbaum, B., \& Moss, M. (2012). The presence of resilience is associated with a healthier psychological profile in intensive care unit (ICU) nurses: results of a national survey. International Journal of Nursing Studies, 49(3), 292-9. doi:10.1016/j.ijnurstu.2011.09.015

Melrose, K. L., Brown, G. D., \& Wood, A. M. (2015). When is received social support related to perceived support and well-being? When it is needed. Personality And Individual Differences, 7797-105. doi:10.1016/j.paid.2014.12.047

Moody, K., Kramer, D., Santizo, R. O., Magro, L., Wyshogrod, D., Ambrosio, J., ... Stein, J. (2013). Helping the helpers: mindfulness training for burnout in pediatric oncology--a pilot program. Journal of Pediatric Oncology Nursing : Official Journal of the Association of Pediatric Oncology Nurses, 30(5), 275-84. doi:10.1177/1043454213504497

Morrissy, L., Boman, P., \& Mergler, A. (2013). Nursing a case of the blues: An examination of the role of depression in predicting job-related affective wellbeing in nurses. Issues In Mental Health Nursing, 34(3), 158-168. doi:10.3109/01612840.2012.740767

Ohler, M. C., Kerr, M. S., \& Forbes, D. A. (2010). Depression in nurses. CJNR: Canadian Journal Of Nursing Research, 42(3), 66-82.

Pearlman, L.A. \& Saakvitne, K.W. (1995a). Trauma and the therapist. New York: Norton.

Polat, S., Alemdar, D. K., \& Gürol, A. (2013). Paediatric nurses' experience with death: The effect of empathic tendency on their anxiety levels. International Journal of Nursing Practice, 19(1), 8-13. doi:10.1111/ijn.12023

Radloff, L. S. (1977a). Center for Epidemiological Studies Depression Scale. Psyctests, doi: $10.1037 / \mathrm{t} 02942-000$

Radloff, L. S. (1977b). The CES-D Scale: A self-report depression scale for research in the general population. Applied Psychological Measurement, 1(3), 385-401. doi:10.1177/014662167700100306

Sarason, B. R., Sarason, I. G., \& Pierce, G. R. (1990). Traditional views of social support and their impact on assessment. In B. R. Sarason, I. G. Sarason, G. R. Pierce, B. 
R. Sarason, I. G. Sarason, G. R. Pierce (Eds.), Social support: An interactional view (pp. 9-25). Oxford, England: John Wiley \& Sons.

Skinner, E., Edge, K., Altman, J., \& Sherwood, H. (2003). Searching for the structure of coping: a review and cri- tique of category systems for classifying ways of coping. Psychological Bulletin, 129(2), 216-269.

Stacey, S., Osborn, M., \& Salkovskis, P. (2015). Life is a rollercoaster...What helps parents cope with the neonatal intensive care unit (NICU)?. Journal Of Neonatal Nursing, 21(4), 136-141. doi:10.1016/j.jnn.2015.04.006

Stamm, B.H. (2010). The Concise ProQOL Manual, $2^{\text {nd }}$ Ed. Pocatello, ID: ProQOL.org.

Shoji K, Bock J, Cieslak R, Zukowska K, Luszczynska A, Benight C. Cultivating secondary traumatic growth among healthcare workers: The role of social support and self-efficacy. Journal Of Clinical Psychology [serial online]. September 2014;70(9):831-846. Available from: PsycINFO, Ipswich, MA. Accessed December 9, 2015.

Teixeira, C., Ribeiro, O., Fonseca, A. M., \& Carvalho, A. S. (2014). Ethical decision making in intensive care units: a burnout risk factor? Results from a multicentre study conducted with physicians and nurses. Journal Of Medical Ethics: Journal Of The Institute Of Medical Ethics, 40(2), 97-103. doi:10.1136/medethics-2012100619

Turnipseed, D. L. (1998). Anxiety and burnout in the health care work environment. Psychological Reports, 82(2), 627-642. doi:10.2466/PR0.82.2.627-642

Uchino, B. N. (2009). Understanding the links between social support and physical health: A life-span perspective with emphasis on the separability of perceived and received support. Perspectives On Psychological Science, 4(3), 236-255. doi:10.1111/j.1745-6924.2009.01122.x

Welbourne, J. L., Eggerth, D., Hartley, T. A., Andrew, M. E., \& Sanchez, F. (2007). Coping strategies in the workplace: Relationships with attributional style and job satisfaction. Journal Of Vocational Behavior, 70(2), 312-325. doi:10.1016/j.jvb.2006.10.006

Westermann, C., Kozak, A., Harling, M., \& Nienhaus, A. (2014). Burnout intervention studies for inpatient elderly care nursing staff: Systematic literature review. International Journal Of Nursing Studies, 51(1), 63-71. doi:10.1016/j.ijnurstu.2012.12.001

White-Traut, R. (2015). Nurse management of the NICU environment is critical to optimal infant development. Journal Of Obstetric, Gynecologic, \& Neonatal Nursing: Clinical Scholarship For The Care Of Women, Childbearing Families, \& Newborns, 44(2), 169-170. doi:10.1111/1552-6909.12561 
Zhao, Bin, Gao, Ronghua, Geng, Shaoning, et al. (2002). Study on the relationship between coping strategies and anxiety in head nurses. Chinese Journal of Nursing(6), 412-414. 


\section{APPENDIX A \\ STUDY MEASURES \\ Professional Quality of Life Scale (ProQOL)}

When you [help] people you have direct contact with their lives. As you may have found, your compassion for those you [help] can affect you in positive and negative ways. Below are some questions about your experiences, both positive and negative, as a [helper]. Consider each of the following questions about you and your current work situation. Select the number that honestly reflects how frequently you experienced these things in the last 30 days.

1. I am happy.

2. I am preoccupied with more than one person I [help].

3. I get satisfaction from being able to [help] people.

4. I feel connected to others.

5. I jump or am startled by unexpected sounds.

6. I feel invigorated after working with those I [help].

7. I find it difficult to separate my personal life from my life as a [helper].

8. I am not as productive at work because I am losing sleep over traumatic experiences of a person I [help].

9. I think that I might have been affected by the traumatic stress of those I [help].

10. I feel trapped by my job as a [helper].

11. Because of my [helping], I have felt "on edge" about various things.

12. I like my work as a [helper].

13. I feel depressed because of the traumatic experiences of the people I [help]. 
14. I feel as though I am experiencing the trauma of someone I have [helped].

15. I have beliefs that sustain me.

16. I am pleased with how I am able to keep up with [helping] techniques and protocols.

17. I am the person I always wanted to be.

18. My work makes me feel satisfied.

19. I feel worn out because of my work as a [helper].

20. I have happy thoughts and feelings about those I [help] and how I could help them.

21. I feel overwhelmed because my case [work] load seems endless.

22. I believe I can make a difference through my work.

23. I avoid certain activities or situations because they remind me of frightening experiences of the people I [help].

24. I am proud of what I can do to [help].

25. As a result of my [helping], I have intrusive, frightening thoughts.

26. I feel "bogged down" by the system.

27. I have thoughts that I am a "success" as a [helper].

28. I can't recall important parts of my work with trauma victims.

29. I am a very caring person.

30. I am happy that I chose to do this work. 


\section{Brief COPE}

Nurses working in the NICU encounter various forms of stress throughout the day. There are many things people do when they experience stress. These items explore ways you have been coping with the stress related to your job. Each item says something about a particular way of coping. We want to know to what extent you've been doing what the item says. How much or how frequently. Don't answer on the basis of whether it seems to be working or not-just whether or not you're doing it. Use these response choices. Try to rate each item separately in your mind from the others. Make your answers as true FOR YOU as you can.

$1=\mathrm{I}$ haven't been doing this at all

$2=$ I've been doing this a little bit

$3=$ I've been doing this a medium amount

$4=$ I've been doing this a lot

1. I've been engaging in other activities to take my mind off things.

2. I've been concentrating my efforts on doing something about the situation I'm in.

3. I've been saying to myself "this isn't real".

4. I've been using alcohol or other drugs to make myself feel better.

5. I've been getting emotional support from others.

6. I've been giving up trying to deal with it.

7. I've been taking action to try to make the situation better.

8. I've been refusing to believe that negative events I experienced at work happened. 
9. I've been saying things to let my unpleasant feelings escape.

10. I've been getting help and advice from other people.

11. I've been using alcohol or other drugs to help me get through it.

12. I've been trying to see my job in a different light, to make it seem more positive.

13. I've been criticizing myself.

14. I've been trying to come up with a strategy about what to do.

15. I've been getting comfort and understanding from someone.

16. I've been giving up the attempt to cope.

17. I've been looking for something good in my job.

18. I've been making jokes about the stressors I experience at work.

19. I've been doing something to think about my job less, such as going to movies, watching TV, reading, daydreaming, sleeping, or shopping.

20. I've been accepting the reality of the fact that stressful experiences I had at work happened.

21. I've been expressing my negative feelings.

22. I've been trying to find comfort in my religion or spiritual beliefs.

23. I've been trying to get advice or help from other people about what to do.

24. I've been learning to live with it.

25. I've been thinking hard about what steps to take.

26. I've been blaming myself for things that happened.

27. I've been praying or meditating.

28. I've been making fun of the situation. 


\section{Center for Epidemiologic Studies Depression Scale}

Below is a list of some of the ways you may have felt or behaved. Please indicate how often you've felt this way during the past week using the following scale.

$0=$ Rarely or none of the time (less than 1 day)

$1=$ Some or a little of the time (1-2 days)

2 = Occasionally or a moderate amount of time (3-4 days)

$3=$ All of the time (5-7 days)

1. I was bothered by things that usually don't bother me.

2. I did not feel like eating; my appetite was poor.

3. I felt that I could not shake off the blues even with help from my family.

4. I felt that I was just as good as other people.

5. I had trouble keeping my mind on what I was doing.

6. I felt depressed.

7. I felt that everything I did was an effort.

8. I felt hopeful about the future.

9. I thought my life had been a failure.

10. I felt fearful.

11. My sleep was restless.

12. I was happy.

13. I talked less than usual.

14. I felt lonely. 
15. People were unfriendly.

16. I enjoyed life.

17. I had crying spells.

18. I felt sad.

19. I felt that people disliked me.

20. I could not "get going." 